IZA DP No. 8472

Does Diploma Type Matter for Subsequent Academic Achievement? A UAE Case Study

Samer Kherfi

George Naufal

September 2014 


\title{
Does Diploma Type Matter for Subsequent Academic Achievement? A UAE Case Study
}

\author{
Samer Kherfi \\ American University of Sharjah \\ George Naufal \\ American University of Sharjah \\ and IZA
}

Discussion Paper No. 8472

September 2014

\author{
IZA \\ P.O. Box 7240 \\ 53072 Bonn \\ Germany \\ Phone: +49-228-3894-0 \\ Fax: +49-228-3894-180 \\ E-mail: iza@iza.org
}

\begin{abstract}
Any opinions expressed here are those of the author(s) and not those of IZA. Research published in this series may include views on policy, but the institute itself takes no institutional policy positions. The IZA research network is committed to the IZA Guiding Principles of Research Integrity.

The Institute for the Study of Labor (IZA) in Bonn is a local and virtual international research center and a place of communication between science, politics and business. IZA is an independent nonprofit organization supported by Deutsche Post Foundation. The center is associated with the University of Bonn and offers a stimulating research environment through its international network, workshops and conferences, data service, project support, research visits and doctoral program. IZA engages in (i) original and internationally competitive research in all fields of labor economics, (ii) development of policy concepts, and (iii) dissemination of research results and concepts to the interested public.
\end{abstract}

IZA Discussion Papers often represent preliminary work and are circulated to encourage discussion. Citation of such a paper should account for its provisional character. A revised version may be available directly from the author. 
IZA Discussion Paper No. 8472

September 2014

\section{ABSTRACT}

\section{Does Diploma Type Matter for Subsequent Academic Achievement? A UAE Case Study}

We examine how selected high school characteristics - including type of diploma - contribute to students' academic success in an American-type university in the United Arab Emirates (UAE). We find no robust evidence that US, UK, and UAE systems of high school diploma produce different outcomes, once we control for English proficiency. Irrespective of the type of diploma, high school grade is a strong positive predictor of future performance. We identify significant female, nationality, and family income effects. There is evidence that school ownership (private versus public) does not matter, and that graduates of coeducational schools perform better.

JEL Classification: A20, I20

Keywords: students' university performance, high school characteristics, diploma, UAE

Corresponding author:

Samer Kherfi

Department of Economics

American University of Sharjah

PO BOX 26666

Sharjah

UAE

E-mail: skherfi@aus.edu 


\section{Introduction}

There is consistent evidence that individuals who perform well in high school accumulate more years of education and obtain higher grades in post-secondary institutions (Rivkin, 1995, for example). In turn, university students who receive better grades are more likely to have a successful future labor market experience (Jones and Jackson, 1990). Loury and Garman (1995) find that university quality is an important determinant of individual earnings. From a macro perspective, human capital accumulation and technological progress are essential to sustained growth and social development. Formal education increases productivity, raises the capacity to innovate and adopt technology, and generates positive economic and social spillovers. Furthermore, as consumption good, education directly c o n t r i b u te s to the quality of life. As a result, investing in schooling is a high priority to many individuals and governments.

However, Hanushek's (2003) review of an extensive literature concludes that, beyond a certain point, additional quantitative resources - such as lowering the students to teacher ratio - have a limited or insignificant impact on different outcomes, including test scores. In searching for a significant quality dimension to explaining the variation in educational quality, part of the literature examines the effect of school type. Using data from UK universities, Smith and Naylor (2005) show that students who attend an independent (or private) school perform less well, at the university level, than those who attend a state-owned high school. However, Hoare and Johnston (2010) report no significant difference between independentschool and state-school students, based on examination performance at a UK university. Horowitz and Spector (2005) point to a favorable but temporary effect from attending religious schools on students' tertiary achievements. Birch and Miller (2007) and Mora and Escardbul (2008) show a positive impact of graduating from private high schools on achievement at two universities in Australia and Spain, respectively. Berkovitz and Hokestra (2011) find that enrollment in a selective private high school increases the chance of attending a selective university.

While the literature has extensively examined various school-related factors, there is limited knowledge on the impact of the type of diploma the school awards. Altonji (1995) finds modest effects of the variation in US high school curriculum, defined as cross-student differences in course selection, on postsecondary education and wages. Our main purpose is to complement the current literature, by analyzing the effect of variations across -as opposed to within- curricular systems, as a potential determinant of educational quality. Differences in highschool diploma type reflect differences not only in the content and weights assigned to the chosen subjects of study, but als o in the way students are assessed, and in the values each diploma espouses. In our data, some schools each offer more than one type of 
diploma. In particular, we examine the role of three popular diploma types (American, British, and UAE) in explaining the variation in students' grades at the American University of Sharjah (AUS), a US-accredited institution of higher education in the UAE. We also examine the effects of main school characteristics - ownership type (public or private) and coeducational status (single-sex or mixed) - and control for a number of student-related factors (gender, nationality, high school performance, English proficiency, major of study, cohort, and family income). Hence, another contribution of this study is in presenting non-existent micro-econometric evidence on education quality in Arab Middle East and North Africa, an issue of great importance given the young-age structure of the region's population, and the serious concerns about the high unemployment rate among its educated youth.

The diverse educational system in the UAE creates a unique opportunity to look into whether the type of diploma matters for subsequent academic achievement. The large and diverse foreign population in the UAE - 80 percent of the total count ( 9.2 million people) has not only contributed to economic prosperity and demographic shift, but has also led to the coexistence of different and popular educational systems. We take advantage of that assortment of systems by looking at how different school diplomas prepare students for an American-style university education. We follow an outcome-oriented approach to assessment in that we do not attempt to investigate the differences across high schools but rather evaluate their differential effects on postsecondary academic achievement. In this context, the AUS experience is the "common exam" to which students with different high school diplomas are subjected. The paper is a case study, because our results are - by designconditional upon students satisfying AUS standards. As we discuss below, the findings are nevertheless indicative to education stakeholders outside the university. In the remainder of the paper, we discuss the data in Section 2, present and interpret the empirical evidence in Sections 3 and 4, address selection issues in Section 5, and summarize the main findings in Section 6.

\section{Data}

AUS was among about 100 private institutions - including branch campuses of international universities - and 3 federal (public) institutions that served close to 100,000 undergraduate students, of which 61 percent were Emiratis (i.e. UAE nationals) in 2011-12. In the same year, Almost 92 percent of foreign students registered in private institutions, whereas 54 percent of Emiratis enrolled in public universities. Inside the public (private) bachelor-awarding sector, 88 percent (42 percent) of the undergraduate students were UAE nationals (Centre for Higher Education and Statistics (CHEDS), 2012).

We used administrative records on all (4482) AUS undergraduate students who enrolled 
between the fall 2004 and spring 2009 semesters. In addition to information on each student's academic record (date of first enrollment, cumulative grade point average (GPA), credit hours, and major field of study), the data reported students' nationality, gender, type of high school diploma, high school name, overall grade in the final year of high school, and Test of English as a Foreign Language (TOEFL) score. We linked the school name to information from the various educational zones of the UAE, about the curriculum the school offered, whether it was privately or publicly owned, and whether it offered singlesex education or coeducation. Also available was information on the household income of applicants for internal (AUS-provided) financial assistance. Student anonymity was preserved throughout the study.

The original data covered the three groups of AUS students: UAE nationals, foreign students who graduated from UAE high schools, and graduates of foreign high schools who subsequently moved to the UAE and attended AUS. The high school background of the latter group of students was quite heterogeneous, because they came from many countries, each of which with its distinctive educational system. In addition, we had limited information about the characteristics of the schools outside the UAE. Therefore, we limited our sample to the first two groups of students.

Furthermore, we removed from the sample, schools that were each represented by one student, in order not to confuse school and individual effects. Also, we dropped the observations on students who obtained, from within the UAE, diplomas that had a relatively small count in our data (adding up, together, to less than 6 percent of the remaining sample). The different innate nature of these degrees prevented lumping them all in one "other diploma" category. After excluding students with incomplete records, the sample on which we conducted our regressions contained 2758 observations.

\section{TABLE 1 HERE}

Table 1 presents summary statistics on the key variables of this study. The data reflect the diversity of the UAE. Students came from 62 countries in the reduced sample. Forty seven percent of the students obtained the US high school diploma, 33 percent received the UK diploma, and 20 percent graduated from high school with the UAE diploma. According to 2009 Ministry of education statistics, in Dubai and Sharjah, the two cities from which AUS draws most of its students, 10 percent of non-Emirati secondary school students attended public schools. On the other hand, in the same two cities, 23 percent of Emirati secondary education students were in private schools. The share of annual enrollment to total enrollment at AUS has consistently increased between fall 2004 and spring 2009, indicating an expanding university.

The statistics in Table 1 did not change much when applied to all 4482 students (rather than 
to the reduced set used in the study), except with regards to student nationality. The focus on local schools increased the share of Emiratis from 14 percent to about 20 percent, because almost all the students who graduated from high schools located abroad were not UAE nationals.

The data on the distribution of students by selected high-school features reveal that only public schools offer the UAE diploma as a stand-alone program, and that public and private schools offering this diploma, alone or in combination with other diplomas, are gender-segregated. Of a total of 115 schools, 36 were public (representing 7 percent of the students). Thirteen private schools, with about 10-percent of the students, taught the UAE curriculum only. And about 13 percent of the students came from 10 schools that offered the UAE diploma, in addition to US and/or UK diplomas. Finally, the student majority (almost 70 percent) graduated from 56 schools that used non-UAE curricula (US and/or UK diplomas), with about one third of this majority graduating from coeducational institutions.

Given that AUS is a coeducational American- style institution of higher education, it is our interest to see if US- (or UK-) curriculum-based schools better prepare students to academic life at AUS, when compared to UAE-curriculum based schools. Also, of particular interest is the fact that English is the language of instruction for students following the UK or US curriculum, whereas Arabic is the language of instruction for students of the UAE curriculum, who also devote considerably more time to religious studies. Therefore, diploma variations between and within schools (some schools offer multiple diplomas) should help in detecting the impact of high-school diploma type on subsequent university performance. We set the US diploma as the benchmark to which the other two diplomas are compared, for two reasons: Students with a US diploma constitute the largest group in our sample and AUS offers American-style tertiary education.

Distinguishing Emiratis from other nationals is warranted for a number of factors. Firstly, admission is more selective when recruiting non-UAE students, because A US has for Emiratis an enrollment quota that has been n o n binding so far. Secondly, Emiratis face a significantly different opportunity set upon graduation (more favorable labor market conditions), and therefore have incentives to put in less study effort, other things being equal. UAE nationals who are not self-employed or part of a family business have so far managed to fill jobs in the protected public sector, where wages and benefits are high, and lifetime employment is the norm. Only 1 percent of Emiratis, who constitute 10 percent of the workforce, are employed in the more competitive private sector. Finally, UAE nationals naturally receive more aid from the government. Emirati students, who are predominantly graduates of public schools, attend public institutions of higher education free of charge, and most those who join private institutions abroad or in the UAE are government-sponsored. 


\section{Estimation and Results}

We adopt the standard education production function approach to estimation, according to which output or academic achievement depends on a number of inputs, most of which are predetermined (pre-AUS). The exceptions are the study major and credit hours earned. Our measure of achievement (the dependent variable) was either the student's GPA as of fall 2012 or at the conclusion of his/her first year (3 semesters) at AUS. GPA varied between a minimum of zero and maximum of 4 . Students who drop out have a lower GPA and fewer credit hours. Those with more credit hours are expected to have a higher GPA because they are more likely to have repeated a course in order to limit the impact of an unsatisfactory grade. We control for the expected positive relationship between GPA and accumulated hours, by including in the regression the sum of the credit hours used as weights in GPA calculations.

We used the student's overall grade in the final year of high school (HSG), as a measure of academic readiness at the time of enrollment. HSG indirectly reflect the non-academic conditions prior to AUS, such as family background, and is a proxy for innate ability. To assess English language skills, we used TOEFL scores (TFL). Admission to AUS is primarily conditional on HSG and TFL. Most of the other independent variables were binary. MAN took the value of 1 if the observations described a man, NAT equaled 1 if the individual was Emirati, $\mathrm{COE}$ equaled 1 if the student attended a coeducational secondary institution, PUB was 1 if the he/she graduated from a public school, and SPR was set at 1 if the student started his/her studies in the spring term. In each case, the dummy variable was set to zero if the corresponding condition was not satisfied.

We differentiated public schools from private schools because, in theory, the former tend to be more financially constrained. In addition, public and private schools manage resources differently and, as a result, offer distinct academic environment. However, the financial factor might not be important in the UAE case. The country is wealthy and per-capita income is among the highest in the world. And despite the absence of income taxes, successive government budgets have recorded considerable surpluses.

To allow more degrees of freedom, we grouped the 26 study majors into 4 broad categories: Business studies (BUS), engineering and physical sciences (EPS), architecture and design (ARD), and humanities and social sciences (HSS). The first and third groups represent fields of study offered in the School of Business and Management (SBM) and the College of Arts, Architecture and Design (CAAD), respectively. Group 4 combines College of Engineering (CEN) majors as well as those offered under the science banner in the College of Arts and Sciences (CAS), whereas group 4 represents the arts section of CAS. Controlling for the major subject of study reflects the views that majors vary in their level of difficulty, 
and that the academic units which offer them tend to adopt sufficiently different approaches to assessment. The data clearly indicated that gender and major interacted in important ways. Two thirds of AUS male students, but only one quarter of female students, chose to study EPS. Therefore, male-female differences could partially represent differences in the subjects studied, or vice versa, hence the need to control for both gender and major. In addition, the student's major correlated with the type of high-school diploma earned. Two thirds of UAE-diploma holders majored in EPS, compared to 36 percent and 46 percent for US- and UK-diploma holders, respectively. We included the high school diploma factor as a set of two dummy variables. UK was equal to 1 if the student had a British diploma, and zero otherwise, whereas UAE was set to 1 if he/she earned an UAE diploma, and zero otherwise, with the US diploma serving as the reference category.

Furthermore, we introduced a set of indicator variables representing the five student cohorts between 2004-05 and 2008-09, to account for possible time-dependent changes that were common to all enrolled students (internal assessment standards, for example), and to control for differences across enrollment cohorts (admission standards). We note that all increases in admission requirements occurred annually in the fall, and applied uniformly across all fields of study.

Although HSG controls for innate ability and prior academic preparedness, students of different schools are possibly drawn from different distributions. If average unobserved ability (such as effort or motivation) varies by school, students who share the same observed characteristics will produce different academic performance at AUS. Therefore, in order to control for other systematic time-invariant school-related characteristics, we include in one specification a set of dummy variables, one for each school. Finally, we ignored a number of factors that displayed very limited variation in our sample, such as student's age (for a given cohort), marital status, and enrollment status (part-time versus full-time). The overwhelming majority of students were unmarried, full-time students.

\section{TABLE 2 HERE}

Applying Ordinary Least Squares (OLS) estimation to the cross-sectional data produces the parameter estimates and their standarderrors in Tables 2 and 3. The estimates for four variations of our model, when applied to the entire dataset, are in Table 2. The presence of school-specific fixed effects distinguishes Regression (2) from Regression (1). In Regression (4), the high school curriculum indicator interacts with HSG and therefore affects GPA only indirectly. Regressions (3) and (4) add two regressors, COE and PUB, and drop the school fixed effect because, in our data, it is nearly perfectly correlated with the two added variables. Therefore, for a given regression, we had to include either COE and PUB or the fixed effects. We estimated the regression equations with and without these effects. In the paper, we present the equations that include COE and PUB, and report any important differences between them and the corresponding fixed effect regressions 
(which are available from the authors upon request).

As expected, and irrespective of the specification, high school performance was a robust predictor of academic achievement at the university level. The effect of HSG was significantly positive; a 10-point increase in HSG raised GPA by about $0.35-0.38$. Having a stronger command of English upon entry predicted better academic results. On average, a 40-point increase in TOEFL score (about one standard deviation change) was associated with 0.08-0.12 increase in GPA, depending on the specification. Furthermore, there was strong evidence that men did not perform as well as women. The negative male effect was quantitatively important, with an average gender gap in GPA of about 0.14 points in favor of women, other things being equal.

In addition, the average GPA of Emirati students was lower than that of other students by about $0.07-0.09$ points, other things being equal. As described earlier, UAE nationality can rationally be associated with lower unobserved effort or motivation, and thus lower GPA because, ceteris paribus, UAE students face on average more favorable local labor market conditions upon graduation.

The results of Table 2 also show that average GPA decreased progressively from the oldest to the youngest student cohorts, despite increasing admission standards over the period of study. The negative cohort effect on GPA is possibly a reflection of the status of AUS internal standards, which appear to have increased as the young university (founded in 1997) matures. In addition, we find that students who joined AUS in the spring semester performed no worse than those who were admitted in the fall semester, against the hypothesis that spring enrollment may point to unfavorable students' characteristics that prevent them from starting their studies as per standard admission dates. Furthermore, GPA rises with the credit hours accumulated, reflecting attrition (students who drop out have smaller hours) and learning by doing (students who repeat a course tend to obtain a better mark).

There was consistent evidence that students majoring in EPS or ARD had significantly lower GPA than BUS or HSS majors, pointing to differences across the majors in either their degrees of difficulty or methods of assessment. The EPS effect was more pronounced $(-0.22$ points versus -0.09 for ARD). Because there was no major or college-specific minimum admission GPA, the effect was unlikely to run from GPA to major.

As for the main variable of interest, diploma type, the results revealed no support to the hypothesis that, on average, US diplomas better prepared students to AUS education. Once English language proficiency was controlled for, there was no evidence showing that UAE diploma holders were disadvantaged. This result was unexpected, because one might conjecture that producing a given level of performance was more difficult for students who transit from one system (UAE-style education in high school) to another (US-style 
education at the university level), other factors held constant. The effect of the UK diploma on GPA was inconclusive as it depended on model specification. Regressions (1), (3), and (4) reveal that UK diploma students performed less well. However, when the school fixed effects replaced COE and PUB (Regression 2), the UK diploma impact disappeared, suggesting perhaps the presence of an unobserved school-specific characteristic that correlated with the UK diploma.

A results-oriented approach to assessment therefore indicates that the US, UAE, and UK curricula are not sufficiently different in terms of preparing students for an American style tertiary education, apart from their primary language of instruction. In light of recurrent calls to substantially revise the UAE curriculum, our results suggest instead a more limited scope of reform, focused on improving the instruction of English as a second language. Indeed, we found that English proficiency was an important determinant of performance. Furthermore, our TOEFL scores by diploma type showed that, on average, UK diploma holders had better command of English than US diploma holders (TFL score: 588 versus 567), who in turn ranked better than UAE diploma holders (TFL score: 529). When we estimated Regression (3) without controlling for TFL (not reported), only then the average performance of UAE diploma holders became significantly worse than that of the reference group (US diploma holders). The policy implications to this outcome are likely to go beyond AUS, because English is also the language of instruction at many public and private institutions of higher education in the country.

Measuring high school performance using high school scores implies that they are comparable across schools, a common implicit assumption in the literature. To account for possible variation in quality across schools offering different diplomas (and perhaps, as a result, applying different assessment methods), we introduced the type of diploma differently in Regression (4), as an interaction with HSG, which amounted to addressing the question: Did the effect on academic performance at AUS, of a unit increase in the high school grade, depend on whether this grade was earned to fulfill the requirement of a UAE, UK, or US diploma? In this context, one could think of the diploma type as one possible dimension of quality differences in education. The results of such change in how diploma type affects GPA, does not alter our findings, as Regressions (3) and (4) show. On average, the positive effect of HSG on GPA was similar among holders of the US and UAE diplomas. The statistically significant negative effect of having a UK diploma on GPA disappeared again when the fixed effects were introduced to the model.

Apart from the finding that the UK-diploma coefficient was consistently insignificant with the fixed effects but significantly negative without them, the results were not sensitive to the presence of the fixed effects. That is, the other coefficients were qualitatively and quantitatively similar across the regressions. The outcome that stands out is that, on average and after controlling for English proficiency and other factors, student performance at the 
tertiary stage is essentially a function of his/her innate ability and formerly-acquired knowledge and skills, irrespective of which high school system is selected to deliver and nurture them.

Regressions (3) and (4) indicate that students from coeducational schools do better, and that public- and private-school students are not different. However, these findings can be imprecise because COE and PUB are quasi perfectly correlated. An alternative approach, therefore, was to assess their effects independently, as we explain below.

\section{Subgroup analysis}

In this section, we test the robustness of our results, by applying the benchmark Regression 3 in Table 2 to meaningful subsets of the data. Table 3 displays five regressions, labeled from (5) to (9). In Regression (5), we look at the determinants of students' GPA at the end of their first year at AUS (i.e. after a maximum of three semesters of enrollment). The underlying idea is that high school effects tend to decay over time due to the influence of university experience. As students become more accustomed to university life and study, or drop out from the sample after the freshmen year, the high-school effect fades away. In other words, presence at AUS tends to soften the school effects as students adjust to university environment and requirements. The common university environment may eventually push individuals from different secondary school backgrounds towards a higher degree of conformity in academic and non-academic behavior. The pre-AUS variables were unaffected, whereas credit hours and field of study were adjusted to reflect students' conditions after one year at AUS. And although students do not usually start major-specific courses during the first year, their actual or intended field of study still affects the choice set of courses available in that year.

\section{TABLE 3 HERE}

Regressions (3) and (5) share similar findings; HSG, TFL, and CRH are positively associated with GPA, whereas being a man or majoring in EPS lowers GPA. SPR and HSS remain insignificant. On the other hand, notable differences between regressions (3) and (5) exist; the cohort year, nationality, and ARD are no more significant in Regression (5). The absence of a cohort effect during the first year suggests that the increasing-internalstandards hypothesis might be affecting upper- level courses following student specialization. In addition, the UAE diploma seems to help students perform better during their first year (with a 10 percent significance level), in contrast to the earlier finding that the UAE and US diploma effects are not different. The UK diploma effect is again inconclusive. It is significantly negative in Regression (5), but becomes insignificant when the regression is reestimated with fixed effects. These effects do not significantly alter the other coefficients. 
Finally, compared to Regression (3), COE and PUB switch significance in Regression (5). As explained earlier, removing both COE and PUB did not change the other coefficients, and retaining only one of them would not make interpreting the included coefficient any easier (COE and PUB are highly correlated). Therefore, we tried a different approach.

In order to examine the effect of high-school coeducation on performance at AUS, we limited the sample in regression (7) to students who held non-UAE diplomas. Because these students came from private schools only, PUB naturally dropped out from the model. In terms of direction and significance, all the results of the reference regression (3) held in Regression (7). In particular, coeducation in high school was positively related to performance at AUS, but only at the 10 percent level of significance. Also, students with a US diploma did better than students with a UK degree when the fixed effects were absent, and the two groups were not different otherwise.

We used a similar approach to examine the effect of school ownership (public versus private). Schools could only offer the UAE diploma in a single-sex setting, irrespective of ownership status. Therefore, restricting our sample to students with this type of diploma eliminated COE, thus capturing the independent impact of PUB on GPA, as shown in Regression (8). The results indicated that public schools were not different from private schools, judged by the average performance of students. Furthermore, the cohort year, gender, and UAE nationality were not significant anymore. All the remaining coefficients lent support to the results of Regression (3), although the number of observations in Regression (8) -549- was considerably smaller.

Students who apply for AUS need-based financial assistance report their family income. Therefore, in Regression (9), we augment Regression (3) by income (INC) as a proxy for the student's socio-economic background. Naturally, we had income figures for a subset of the students (the applicants). The count of Emiratis receiving AUS aid was small, either because their household income was not low enough, or because they benefited from external scholarships. For this reason, we excluded nationality from Regression (9). The smaller set of income data still displayed considerable and thus useful variation. The $90^{\text {th }}$ percentile income was about four times its $10^{\text {th }}$ percentile. The variation in income had a positive and significant impact on academic performance. And the effect was quantitatively strong. A 10 percent increase in income contributed to a rise in GPA by 0.7 points. The positive effect was in line with results reported elsewhere. Betts and Morell (1999) found that household income contributed positively to students' success, whereas Smith and Naylor (2001) reported that students from socially higher occupational backgrounds performed better. The INC-related result suggests that financial aid may have a short-term counter (positive) effect on achievement among students from low-income households. As for the other determinants of GPA, Regression (9) reproduced almost all the findings of Regression (3). In Regression (9), UAE diploma holders performed less well than US diploma holders and better than UK 
diploma holders. With the fixed effects replacing COE and PUB in Regression (9), the negative impact of the UK curriculum remained, whereas the effect of the UAE diploma vanished.

\section{Selection Issues}

Conditional upon nationality, there is no reason to believe that the average student who enrolls at another university and who meets AUS HSG and TFL admission requirements is different in terms of motivation, effort, or other unobserved characteristics from the average AUS student, because these characteristics tend to be positively correlated to the control variables. Of course, universities have different enrollment standards and UAE/other nationality mix, and therefore may well attract students with different average unobserved attributes. We cannot accurately predict how self-selection might affect our estimates because no specific information on non-AUS students is available. However, if higher AUS admission standards attract students who are more motivated, for example, the estimated coefficients of HSG and TFL will be biased upward, implying the need to be cautious about interpreting the results in terms of the general population of students. What follows is an attempt to outline how unobserved characteristics might vary along three determinants (nationality, gender, and family income) between AUS and other university students.

While UAE nationals can choose to study at tuition-free public universities, the government sponsors most of their studies if they select to attend AUS. Thus, among qualified Emiratis, the decision to join AUS is likely to be insensitive to financial considerations. On the other hand, with few exceptions, foreigners in the UAE can only attend fee-charging private institutions, so selecting to be at AUS in this case, is likely to be influenced by fee differentials across universities and, consequently, by the socioeconomic status of the student. It is difficult to think of a priori systematic (positive or negative) link between unobserved determinants of performance and socio-economic status. A lower status may increase student's motivation to break away from it, or may decrease his/her motivation due to a developed sense of helplessness, other things being equal. Among Emiratis, the decision to join AUS is perhaps more related to whether the student and his/her family prefer the American coeducational learning environment, given that public universities in the UAE are gender-segregated. There is no reason to suspect that preference towards mixed education is non-randomly related to unobserved ability. However, this preference probably interacts with gender. Due to the rather conservative character of the typical Emirati family, it is much more common for men than women, to travel regionally or internationally for higher education. As a result, the top qualified or motivated men are more likely than their female counterparts to study abroad, which might partially explain why, on average, UAE women outperform UAE men at AUS. In this context, by offering American education at home, AUS represents to some families a desirable compromise that has more value if the student is a woman. Other gender-specific explanations include the fact that, 
due to cultural and religious factors, UAE men have more choices for, and spend more time on, "distracting" leisure activities, so women study longer. A related argument is that, in the same environment, women study harder because excelling in education is often an effective way to empower them and relax the constraints they face.

Additionally, the percentage of AUS foreign students who attended UAE public $\mathrm{h}$ i g h schools was 7 percent, a figure close to that of Dubai and Sharjah (10 percent), the two cities from which AUS students are drawn primarily. The share of public-school attendance in our sample was 8.3 percent among UAE nationals, which was considerably lower than the Dubai-Sharjah rate (77 percent). Therefore, most UAE nationals in our data came uncharacteristically from private schools. Because we controlled for gender, nationality, and school type, our results are representative and can be generalized, as long as UAE students in private schools are not systematically different from their counterparts in public schools, along some unobserved dimensions that correlate with GPA (for instance, if private school students are more, or less, motivated and ambitious). As a result, in the case of Emirati students only, we are cautious not to extend our findings to the Emirati student population. With regards to non-UAE students, their characteristics are likely to be similar to characteristics of the general population of foreign students, subject to meeting AUS admission standards.

Regression (6) in Table 3 further explores the issue of self-selection. We apply Regression (3) to AUS students in the lowest $25^{\text {th }}$ percentile of the high school grade distribution. These students are more likely than the rest of AUS entrants to resemble those who join other universities in the UAE, under the assumption that AUS admission standards are higher. In other words, the average characteristics of the $25^{\text {th }}$ percentile group will be closer to the average characteristics of the population of university students in the UAE. Our findings with respect to the entire sample hold for its lower quartile. Again we found that HSG and TFL were strong predictors of success, that being male, UAE national, or science/engineering student negatively and significantly affected performance and that GPA w as decreasing over time. In addition, there was no difference in outcomes between graduates of US and UAE schools, who again performed better than graduates of UK schools only when the fixed effects were absent from the equation. Also matching Regression (3) outcome was the insignificance of spring enrollment and public ownership of school. The main change associated with the lower-quartile regression was that COE and ARD were no longer significant. The overall parameter stability therefore suggests that selection may not be a serious concern. In addition, we had information on the math SAT scores of about 300 new students in 2008-09, who mostly held the US high school diploma. Their average score of 530 was close to the 55th percentile of the math SAT score in the US. This partial evidence indicates that, at least with respect to math skills, the average AUS student is not very different from his US counterpart, who had an average and median score of 515 in 2009. 
CHEDS (2012) data permit further comments on the external validity of our results. During the academic year 2011-12, there were close to 25000 new undergraduate students in the UAE, who had an average (passing) high school score of 81 percent. Their $25^{\text {th }}, 50^{\text {th }}$, and 75 th percentile scores were 74, 81.5, and 89 percent, respectively. Given that the minimum HSG required for admission to AUS in 2011 was 80 percent, it is safe to assume that our students are drawn from at least the top 50 percent of the distribution of undergraduate higher education students in the UAE. In addition, the minimum HSG in the data was 70 percent (the admission cut-off score before 2005). If the UAE distribution of HSG (of 50 percent and above) did not shift in any serious way, a reasonable assumption for a study period of 5 years, then our sample data are likely to come from roughly the top 75 percent of the HSG distribution. Also, a good number of students from the bottom 25 percent of the passing score do not enroll in a four-year (bachelor) degree program. Upon a recent review of the standards for admission to bachelor programs in UAE universities, we found that the reported minimum HSG was 60 percent. Furthermore, the minimum score at the two public universities (70-75 percent) was not very different from that of AUS. As such, our sample likely covers more of the distribution of students who attend a bachelor-granting program in the UAE, because the CHED percentile numbers listed above were based on UAE data that included post-secondary diploma students, who were more likely than bachelor students to have lower percentile scores.

\section{Conclusion}

This paper examines how three high-school characteristics - namely curriculum or diploma type, ownership form (private or private), and coeducational status (single-sex education or not) - affect students' achievement in subsequent postsecondary education. We take advantage of the diverse educational scene in the UAE, to see to what extent US, UK, and UAE-based curricula have differential effects on students' academic performance at a university in the UAE.

We find no evidence that the UAE and US curricula are sufficiently different in terms of preparing students for an American style tertiary education, once English proficiency is controlled for. Also, some evidence that UK diploma holders are disadvantaged is not robust and is sensitive to model specification. The results confirm that high school grade is a strong positive predictor of students' university GPA. Students' achievement at the tertiary stage is essentially a function of their knowledge and skills, regardless of the educational system that delivers them. At the domestic level, and despite recurrent calls to substantially revise the UAE curriculum, our results suggest instead a more limited scope of reform, focused on improving the instruction of English. The analysis shows that UAE diploma holders lag behind other diploma holders in English proficiency, and that the latter is an important positive determinant of success at AUS. The policy implications to this outcome go beyond AUS, because English is also the language of instruction at many other institutions of higher 
education in the country, including public universities whose students overwhelmingly hold the UAE high school diploma. Being male or UAE citizen is significantly associated with lower GPA. UAE nationality can rationally be associated with lower unobserved effort or motivation, and thus lower GPA, because Emirati students face more favorable local labor market conditions upon graduation. Possible explanations for the female premium can be cultural and relate to the rather conservative character of the UAE society. One explanation is that because it is easier for men to travel abroad to seek education, and many talented UAE nationals do so, it is possible that compared to women, men with favorable unobserved attributes are under-represented in the sample. Another explanation is that the stricter code on what women can and cannot do, compared to men, creates conditions in which men spend relatively more time on leisure activities. These same conditions, it is argued, encourage women to exercise more effort, as they place more value on education as a means to empowerment.

Subgroup regressions reveal additional results. Among non-UAE diploma holders, high school coeducation is positively associated with performance at AUS. And a smaller set of observations on UAE diploma holders, who graduate from single-gender institutions, shows no difference between public and private secondary schools, in terms of students' performance at AUS. In addition, family income has a significant, positive impact on university success among financial aid applicants, supporting the well-established evidence on the positive influence of better household conditions.

Our results can only be generalized to other university students who meet AUS admission standards. We applied our benchmark regression to AUS students in the lowest 25th percentile of the high school grade distribution, students who are more likely to resemble the average student in the UAE. The findings with respect to our entire sample hold for its lowest quartile. Finally, we provide some evidence that the average AUS student is unlikely to be very different from the one that joins the other main universities in the country, especially if he/she is an expatriate. 


\section{References}

Altonji, J. "The Effects of High School Curriculum on Education and Labor Market Outcomes" The Journal of Human Resources 30(3) (1995): 409-438

Berkowitz, D. and M. Hoekstra "Does high school quality matter? Evidence from admissions data" Economics of Education Review 30(2) (2011):280-288

Betts J. and D. Morell "The Determinants of Undergraduate Point Average: The Relative Importance of Family Background, High School Resources, and Peer Group Effect" The Journal of Human Resources 34(2) (1999): 268-293

Birch, E. and P. Miller "The influence of type of high school attended on university performance" Australian Economic Papers 46(1) (2007): 1-17

Centre for Higher Education and Statistics (CHEDS) "Indicators of the UAE higher education sector" Report (2012). Retrieved from http://www.cheds.ae/

Hanushek, E "The Failure of Input-Based Schooling Policies" The Economic Journal 113 (485) (2003): F64-F98

Hoare, A. and R. Johnston "Widening participation through admissions policy - a British case study of school and university performance" Studies in Higher Education 36(1) (2010):21-41

Horowitz, J. and L. Spector "Is there a difference between private and public education on college performance" Economics of Education Review 24(2) (2005):189-195

Jones, E. and J. Jackson "College Grades and Labor Market Rewards" The Journal of Human Resources 25(2) (1990): 253-266

Loury L. and D. Garman "College Selectivity and Earnings" Journal of Labor Economics 13(2) (1995): 289-308

Mora T. and J-O. Escardíbul "Schooling effects on undergraduate performance: evidence from the University of Barcelona" Higher Education 56(5) (2008): 519-532

Smith, J., and R. Naylor "Determinants of degree performance in UK universities: A statistical analysis of the 1993 student cohort" Oxford Bulletin of Economics and Statistics (2001) 63: 29-60.

Smith, J. and R. Naylor "Schooling effects on subsequent university performance: evidence 
for the UK university population” Economics of Education Review 24(5)(2005): 549-562

World Bank. The Road Not Traveled: Education Reform in the Middle East and North Africa The World Bank (2008) 


\section{Tables}

Table 1: Descriptive statistics

\begin{tabular}{lrr}
\hline Variable & Mean & $\begin{array}{r}\text { Standard } \\
\text { Deviation }\end{array}$ \\
\hline High school grade (HSG) & 90.102 & 6.240 \\
TOEFL score (TFL) & 566.172 & 44.976 \\
Cumulative grade point average (GPA) & 2.694 & 0.686 \\
Gender (MAN) & 0.509 & \\
UAE national (NAT) & 0.203 & \\
Curriculum type & & \\
American (US) & 0.470 & \\
British (UK) & 0.330 & \\
Emirati (UAE) & 0.200 & \\
Major & 0.323 & \\
Business (BUS) & 0.417 & \\
Engineering/Science (EPS) & 0.112 & \\
Architecture/Design (ARS) & 0.148 & \\
Humanities/Social Sciences (HSS) & & \\
Enrollment year & 0.162 & \\
2004-05 & 0.189 & \\
2005-06 & 0.198 & \\
2006-07 & 0.208 & \\
2007-08 & 0.243 & \\
2008-09 & 0.205 & \\
Spring enrollment (SPR)
\end{tabular}


Table 2: Determinants of academic performance

\begin{tabular}{|c|c|c|c|c|c|c|c|c|}
\hline \multirow[b]{2}{*}{ Dependent variable: GPA } & \multicolumn{2}{|c|}{$\overline{(1)}$} & \multicolumn{2}{|c|}{$\overline{(2)}$} & \multicolumn{2}{|c|}{$\overline{(3)}$} & \multicolumn{2}{|c|}{$\overline{(4)}$} \\
\hline & Coef. & S.E. & Coef. & S.E. & Coef. & S.E. & Coef. & S.E. \\
\hline High school grade - HSG & $0.035 * *$ & 0.002 & $0.038^{* * *}$ & 0.002 & $0.036^{* * *}$ & 0.002 & $0.036^{* * *}$ & 0.002 \\
\hline \multicolumn{9}{|l|}{ High school curriculum (US) } \\
\hline UK & $-0.127^{* * *}$ & 0.023 & -0.049 & 0.049 & $-0.136^{* * *}$ & 0.024 & & \\
\hline UAE & -0.025 & 0.030 & 0.056 & 0.095 & -0.039 & 0.035 & & \\
\hline HSG*UK & & & & & & & $-0.002^{* * *}$ & 0.000 \\
\hline HSG*UAE & & & & & & & -0.000 & 0.000 \\
\hline TOEFL score - TFL & $0.003 * *$ & 0.000 & $0.002 * *$ & 0.000 & $0.002 * *$ & 0.000 & $0.002^{* * *}$ & 0.000 \\
\hline Gender - MAN & $-0.138 * *$ & 0.021 & $-0.149^{* *}$ & 0.022 & $-0.141^{* * *}$ & 0.021 & $-0.140 * *$ & 0.021 \\
\hline UAE national - NAT & $-0.095 \cdots$ & 0.024 & $-0.071^{\cdots *}$ & 0.027 & $-0.095^{* * *}$ & 0.024 & $-0.094^{* * *}$ & 0.024 \\
\hline Credit hours - CRH & $0.008 * *$ & 0.000 & $0.008^{* * *}$ & 0.000 & $0.008 * *$ & 0.000 & $0.008 * *$ & 0.000 \\
\hline \multicolumn{9}{|l|}{ Enrollment year (2004-05l) } \\
\hline 2005-06 & $-0.076^{* *}$ & 0.030 & $-0.079 \cdots$ & 0.030 & $-0.078^{* *}$ & 0.031 & $-0.079^{* * *}$ & 0.030 \\
\hline $2006-07$ & $-0.130 * *$ & 0.031 & $-0.131 \cdots *$ & 0.031 & $-0.131^{* * *}$ & 0.031 & $-0.131^{* *}$ & 0.031 \\
\hline $2007-08$ & $-0.124 \cdots$ & 0.032 & $-0.141^{\cdots *}$ & 0.032 & $-0.126^{* * *}$ & 0.033 & $-0.126^{* * *}$ & 0.033 \\
\hline 2008-09 & $-0.077^{* *}$ & 0.031 & $-0.103 \cdots$ & 0.031 & $-0.078^{* *}$ & 0.031 & $-0.078^{* *}$ & 0.031 \\
\hline Enrollment term - SPR (Fall) & -0.011 & 0.024 & -0.028 & 0.024 & -0.013 & 0.024 & -0.013 & 0.024 \\
\hline \multicolumn{9}{|l|}{ Major (BUS) } \\
\hline ARD & $-0.090^{* *}$ & 0.029 & $-0.096^{* * *}$ & 0.029 & $-0.089^{* * *}$ & 0.029 & $-0.089^{* * *}$ & 0.029 \\
\hline HSS & -0.000 & 0.029 & 0.005 & 0.029 & 0.003 & 0.029 & 0.002 & 0.029 \\
\hline EPS & $-0.225 * * *$ & 0.023 & $-0.225 * *$ & 0.024 & $-0.223^{* * *}$ & 0.023 & $-0.224^{* * *}$ & 0.023 \\
\hline Coeducational school - COE & & & & & $0.046^{*}$ & 0.024 & $0.048^{* *}$ & 0.024 \\
\hline Public school - PUB & & & & & 0.046 & 0.041 & 0.038 & 0.041 \\
\hline Constant & $-2.548 \cdots *$ & 0.186 & $-2.473^{* *}$ & 0.192 & $-2.517^{* * *}$ & 0.187 & $-2.577^{* * *}$ & 0.189 \\
\hline School fixed effects & No & & Yes & & No & & No & \\
\hline Number of observations & 2758 & & 2758 & & 2758 & & 2758 & \\
\hline Adjusted $R^{2}$ & 0.527 & & 0.543 & & 0.527 & & 0.527 & \\
\hline
\end{tabular}

S.E.: Robust standard errors. *,**,**: $10 \%, 5 \%$ and $1 \%$ signiflcance levels, respectively. Reference groups in parentheses. Fixed effects output suppressed. 
Table 3: Determinants of academic performance - subgroups

\begin{tabular}{|c|c|c|c|c|c|c|c|c|c|c|}
\hline \multirow{3}{*}{$\begin{array}{l}\text { Dependent variable: GPA } \\
\text { Student group: } \\
\text { High school grade - HSG }\end{array}$} & \multicolumn{2}{|l|}{ (5) } & \multicolumn{2}{|c|}{$(6)$} & \multicolumn{2}{|c|}{ (7) } & \multicolumn{2}{|c|}{$(8)$} & \multicolumn{2}{|c|}{ (9) } \\
\hline & \multicolumn{2}{|c|}{ First year } & \multicolumn{2}{|c|}{ 25th percentile ${ }^{\star}$} & \multicolumn{2}{|c|}{ UK/US diploma } & \multicolumn{2}{|c|}{ UAE diploma } & \multicolumn{2}{|c|}{ Aid applicants ${ }^{\circ}$} \\
\hline & $0.032^{* * *}$ & 0.002 & $0.023^{* * *}$ & 0.006 & $0.031^{* *}$ & 0.002 & $0.065^{* * *}$ & 0.006 & $0.039^{* * *}$ & 0.003 \\
\hline \multicolumn{11}{|l|}{ High school curriculum (US) } \\
\hline UK & $-0.113^{* * *}$ & 0.024 & $-0.086^{* *}$ & 0.041 & $-0.120^{* * *}$ & 0.024 & & & $-0.187^{* * *}$ & 0.032 \\
\hline UAE & $0.060^{*}$ & 0.034 & -0.058 & 0.095 & & & & & $-0.084^{* *}$ & 0.041 \\
\hline TOEFL score - TFL & $0.002 \cdots$ & 0.000 & $0.002 * *$ & 0.000 & $0.003^{* * *}$ & 0.000 & $0.002 * * *$ & 0.001 & $0.002 * *$ & 0.000 \\
\hline Gender - MAN & $-0.055 * *$ & 0.021 & $-0.175 \cdots$ & 0.037 & $-0.181^{* *}$ & 0.024 & 0.055 & 0.047 & $-0.114^{* * *}$ & 0.030 \\
\hline UAE national - NAT & 0.037 & 0.026 & $-0.095^{* * *}$ & 0.037 & $-0.105^{* \cdots}$ & 0.026 & -0.024 & 0.059 & & \\
\hline Credit hours - CRH & $0.041 \cdots$ & 0.002 & $0.009 * *$ & 0.000 & $0.008 * *$ & 0.000 & $0.007^{* * *}$ & 0.001 & $0.007^{* * *}$ & 0.001 \\
\hline \multicolumn{11}{|l|}{ Cohort year (2004-05) } \\
\hline $20050-6$ & 0.002 & 0.031 & $-0.093^{* *}$ & 0.043 & $-0.083^{* *}$ & 0.033 & -0.016 & 0.071 & -0.053 & 0.041 \\
\hline 2006-07 & -0.026 & 0.032 & $-0.120^{* *}$ & 0.050 & $-0.137^{* * *}$ & 0.034 & -0.055 & 0.073 & $-0.140^{* * *}$ & 0.042 \\
\hline 2007-08 & -0.033 & 0.033 & $-0.152 * *$ & 0.058 & $-0.134^{* * *}$ & 0.037 & -0.024 & 0.066 & $-0.124^{* * *}$ & 0.042 \\
\hline 2008-09 & -0.043 & 0.032 & -0.045 & 0.055 & $-0.081^{* *}$ & 0.035 & 0.005 & 0.071 & $-0.111^{* *}$ & 0.043 \\
\hline Enrollment term - SPR (Fall) & -0.003 & 0.025 & 0.013 & 0.038 & -0.008 & 0.028 & -0.037 & 0.045 & 0.002 & 0.031 \\
\hline \multicolumn{11}{|l|}{ Major (BUS) } \\
\hline $\mathrm{ARD}$ & -0.045 & 0.030 & -0.022 & 0.069 & $-0.071^{* *}$ & 0.031 & $-0.233^{* *}$ & 0.078 & $-0.172^{* * *}$ & 0.039 \\
\hline HSS & -0.003 & 0.032 & 0.049 & 0.040 & -0.018 & 0.031 & $0.140^{*}$ & 0.078 & 0.009 & 0.046 \\
\hline EPS & $-0.042^{*}$ & 0.024 & $-0.176^{* *}$ & 0.043 & $-0.231 * *$ & 0.026 & $-0.240^{* * *}$ & 0.059 & $-0.253^{* * *}$ & 0.033 \\
\hline Coeducational school - COE & 0.029 & 0.024 & 0.035 & 0.038 & $0.041^{*}$ & 0.024 & & & $0.075^{* *}$ & 0.035 \\
\hline Public school - PUB & $0.085^{* *}$ & 0.042 & -0.105 & 0.113 & & & -0.000 & 0.041 & 0.034 & 0.050 \\
\hline $\ln$ (family income) & & & & & & & & & $0.066^{* *}$ & 0.023 \\
\hline Constant & $-2.340 * *$ & 0.189 & $-1.461 * *$ & 0.459 & $-2.167 * *$ & 0.202 & $-5.135 * * *$ & 0.552 & $-3.224^{* * *}$ & 0.367 \\
\hline Number of observations & 2758 & & 822 & & 2209 & & 549 & & 1231 & \\
\hline Adjusted $R^{2}$ & 0.532 & & 0.543 & & 0.540 & & 0.501 & & 0.440 & \\
\hline
\end{tabular}

S.E.: Robust standard errors. $", * *, * * *: 10 \%, 5 \%$ and $1 \%$ signiffcance levels, respectively. Reference groups in parentheses.

${ }^{\star}$ Based on high school grade. ${ }^{\circ}$ Non-Emirati applicants for internal financial aid. 